\title{
Analisis Video Views to Followers Ratio Instagram Pada 5 Brand Gaming Gear Lokal Terbaik
}

\author{
I Wayan Arya Pratama Putra \\ aryapratamaputra888@gmail.com
}

\begin{abstract}
Instagram is one part of communication, namely visual communication where this visual communication can build a person's image, Instagram has 700 million active users globally. Instagram comes from the word "insta" which refers to the word "instant", just like a polaroid camera where the camera produces photos directly or instantly and "gram" which comes from the word telegram, where telegram serves to send information to many people. With so many Instagram users in Indonesia, this is an opportunity for brands to market their products. One of them is gaming gear brands, they market their products on Instagram in the hope of getting customers. The 5 Best Local Gaming Gear Brands, who use Instagram for their promotional media. The 5 Best Local Gaming Gear Brands are: NYK NEMESIS, REXUS ID, Fantech ID, Vortex Series, Digital Alliance. The purpose of this study is to determine the credibility of the performance of the Best Local 5 Gaming Gear Instagram accounts using Video Views to Followers Ratio. This study uses a quantitative exploratory method, and will calculate using the ratios that exist on Instagram.
\end{abstract}

\begin{abstract}
Abstrak
Instagram merupakan salah satu dari bagian komunikasi, yaitu komunikasi visual yang mana komunikasi visual ini dapat membangun citra seseorang, Instagram memiliki 700 juta pengguna aktif secara global. Instagram berasal dari kata "insta" yang mengacu pada kata "instan", sama halnya seperti kamera polaroid yang mana kamera tersebut menghasilkan foto secara langsung atau instan dan "gram" yang berasal dari kata telegram, dimana telegram berfungsi untuk mengirimkan informasi kepada orang banyak. Dengan banyaknya pengguna Instagram yang ada di Indonesia ini menjadikan kesempatan bagi brand untuk memasarkan produk mereka. Salah satunya adalah brand-brand gaming gear, mereka memasarkan produk mereka di Instagram dengan harapan mendapatkan pelanggan. Adapun 5 Brand Gaming Gear Lokal Terbaik, yang menggunakan Instagram untuk media promosi mereka. Adapun 5 Brand Gaming Gear Lokal Terbaik tersebut adalah: NYK NEMESIS, REXUS ID, Fantech ID, Vortex Series, Digital Aliance. Tujuan dari penelitian ini adalah mengetahui kredibilitas performa dari akun Instagram 5 Gaming Gear Lokal Terbaik menggunakan Video Views to Followers Ratio. Penelitian ini menggunakan metode eksploratif kuantitatif, dan akan menghitung menggunakan rasio-rasio yang ada pada Instagram.
\end{abstract}

Keyword : Credibility Account Instagram ; Social Media Marketing ; Social Media Instagram ; Video Views to Followers Ratio Instagram; Brand Gaming Gear Lokal Terbaik. 


\section{PENDAHULUAN}

Pada era globalisasi seperti sekarang, hampir semua aspek yang ada pada di dunia ini sudah berbasiskan teknologi. Seperti halnya aspek komunikasi yang sudah menggunakan basis teknologi dimana komunikasi masa sekarang bisa dilakukan dengan jarak jauh menggunakan sebuah perangkat yaitu handphone. Namun untuk melakukan komunikasi diperlukannya sebuah media yang terdapat dalam sebuah handphone, salah satunya adalah Media Sosial.

Media sosial merupakan media online yang digunakan untuk membantu individu dalam menyampaikan dan memperoleh informasi (Yusi Kamhar and Lestari 2019). Dari pernyataan tersebut social media selain digunakan sebagai alat komunikasi media social juga digunakan sebagai sarana bagi individu dalam mencari dan juga memperoleh informasi yang diinginkannya. Informasi yang terkandung dalam sosial media tidak hanya berupa text ataupun tulisan namun juga bisa berupa gambar dan video. Salah satu contoh media sosial yang populer belakangan ini adalah Instagram.

Instagram merupakan aplikasi yang digunakan untuk berbagi foto yang dapat dilihat oleh Followers dari penggugah foto tersebut dan dapat saling memberikan komentar serta like (Kertamukti et al. 2015). Selain menggugah foto Instagram juga memiliki fitur seperti video pendek, Instagram TV, dan juga market Place. Instagram juga menyediakan layanan komunikasi atau chatting antar pengguna Instagram.

Sebagai media sosial Instagram sering dipergunakan sebagai personal branding atau media untuk mempromosikan diri baik oleh individu maupun sebuah perusahaan. Personal branding merupakan suatu proses ketika seseorang menggunakan dirinya atau kemampuannya sebagai merek dagang, untuk menarik persepsi publik (Ruth and Candraningrum 2020). Instagram memiliki traffic yang menjanjikan yakni sekitar 6,29 milyar pengunjung. Maka dari itu ada beberapa brand yang menggunakan Instagram sebagai media dalam mempromosikan produknya. Contohnya seperti brand Gaming Gear lokal berikut ini : NYK NEMESIS, REXUS ID, Fantech ID, Vortex Series, Digital Aliance ("Inilah 5 Brand Gaming Gear Lokal Terbaik - EXP” n.d.).

Penelitian ini menggunakan metode eksploratif kuantitatif, dan akan menghitung menggunakan rasio-rasio yang ada pada Instagram. Penelitian ini hanya berfokus untuk menghitung kredibilitas Video Views to Followers Ratio pada 5 Gaming Gear Lokal Terbaik. Tujuan dari penelitian ini adalah mengetahui kredibilitas performa dari akun Instagram 5 Gaming Gear Lokal Terbaik menggunakan Video Views to Followers Ratio.

\section{TINJAUAN PUSTAKA}

Seiring perkembangan jaman yang semakin cepat, social media juga bertumbuh dengan pesat. Social media seakan menjadi kebutuhan yang wajib bagi masyarakat luas, dimana social media bukan lagi hanya digunakan sebagai sarana berkomunikasi namun juga digunakan sebagai sarana mengekspresikan diri. Aplikasi social media yang sangat diminati masyarakat diantaranya adalah, TikTok, Instagram, Facebook dan Twitter. 
Instagram merupakan salah satu dari bagian komunikasi, yaitu komunikasi visual yang mana komunikasi visual ini dapat membangun citra seseorang (Kertamukti et al. 2015). Menurut (Soraya 2017) Instagram memiliki 700 juta pengguna aktif secara global. Instagram memiliki beberapa fitur unggulan yang bisa digunakan diantaranya IgTV, Instastory, Feed, video, foto dan fitur terbaru yang baru-baru ini keluar yakni Reels (Sari 2021). Menurut (Untari and Fajariana 2018) Instagram berasal dari kata "insta" yang mengacu pada kata "instan", sama halnya seperti kamera polaroid yang mana kamera tersebut menghasilkan foto secara langsung atau instan dan "gram" yang berasal dari kata telegram, dimana telegram berfungsi untuk mengirimkan informasi kepada orang banyak. Jadi Instagram dapat disimpulkan sebagai aplikasi untuk berbagi gambar secara instan kepada banyak orang

Instagram menekankan posting an yang berupa foto dan video dimana hal ini merupakan suatu keunikan sendiri dari Instagram (Ernayani et al. 2021).Sebagai salah satu media sosial yang populer di Indonesia dimana Indonesia menempati urutan kedelapan di dunia dengan $10 \%$ pengguna Instagram aktif (Ernayani et al. 2021), Instagram tidak hanya digunakan sebagai alat untuk sharing foto, namun Instagram kini banyak digunakan oleh perusahaan untuk memasarkan produknya.

Instagram dirasakan memiliki kekuatan ataupun pengaruh dalam industri, sehingga menimbulkan kualitas akun yang menentukan strata maupun kredibilitas pemilik akun. Kredibilitas akun Instagram merupakan suatu hal yang cukup penting untuk berbagai kepentingan. Kredibilitas sebuah akun TikTok dapat diukur dari tingkat performa yang dihasilkan secara matematis. Dalam mengukur performa diperlukan skala pengukuran yang tertuang ke dalam rasio. 


\section{TINJAUAN PUSTAKA}

Penelitian ini menggunakan metode eksploratif kuantitatif untuk mengetahui kredibilitas dari performa 5 akun brand Gaming Gear lokal terbaik. Metode eksploratif adalah metode penelitian dimana sebuah penelitian berupaya memaparkan dan menggambarkan fenomena, dimana peneliti belum memiliki arah tentang fenomena yang ditelitinya. Metode ini juga merupakan metode pengumpulan data untuk menjawab persoalan yang menjadi minat peneliti.

Tujuan utama dari penelitian ini adalah untuk mengetahui nilai kredibilitas dari performa akun Instagram 5 Brand Gaming Gear lokal terbaik. Ada beberapa langkah yang dilakukan dalam penelitian ini sehingga bisa menemukan peringkat pertama akun brand gaming gear lokal terbaik, langkah-langkah yang dilakukan diantaranya:

\section{a. Melakukan Eksplorasi Pada Website Untuk Menentukan Objek Yang Akan Dianalisa}

Pada langkah pertama ini dilakukan eksplorasi yang bertujuan untuk mencari objek yang pas untuk diteliti, pada beberapa halaman website. Setelah eksplorasi dilakukan dan ditemukan bahwa ada 5 brand gaming gear lokal terbaik, maka langkah selanjutnya adalah memastikan bahwa kelima brand tersebut memiliki akun Instagram.

b. Menghitung Nilai Rata-Rata Variable Dari Top 5 Brand Gaming Gear Lokal Terbaik Pada langkah ini, dimulai perhitungan variable video views dan variable followers. Untuk menghitung nilai rata-rata dari variable video vies dan followers yaitu dengan cara mengambil masing-masing setidaknya 10 video terbaru dari setiap akun dan kemudian menghitung masing-masing variable.

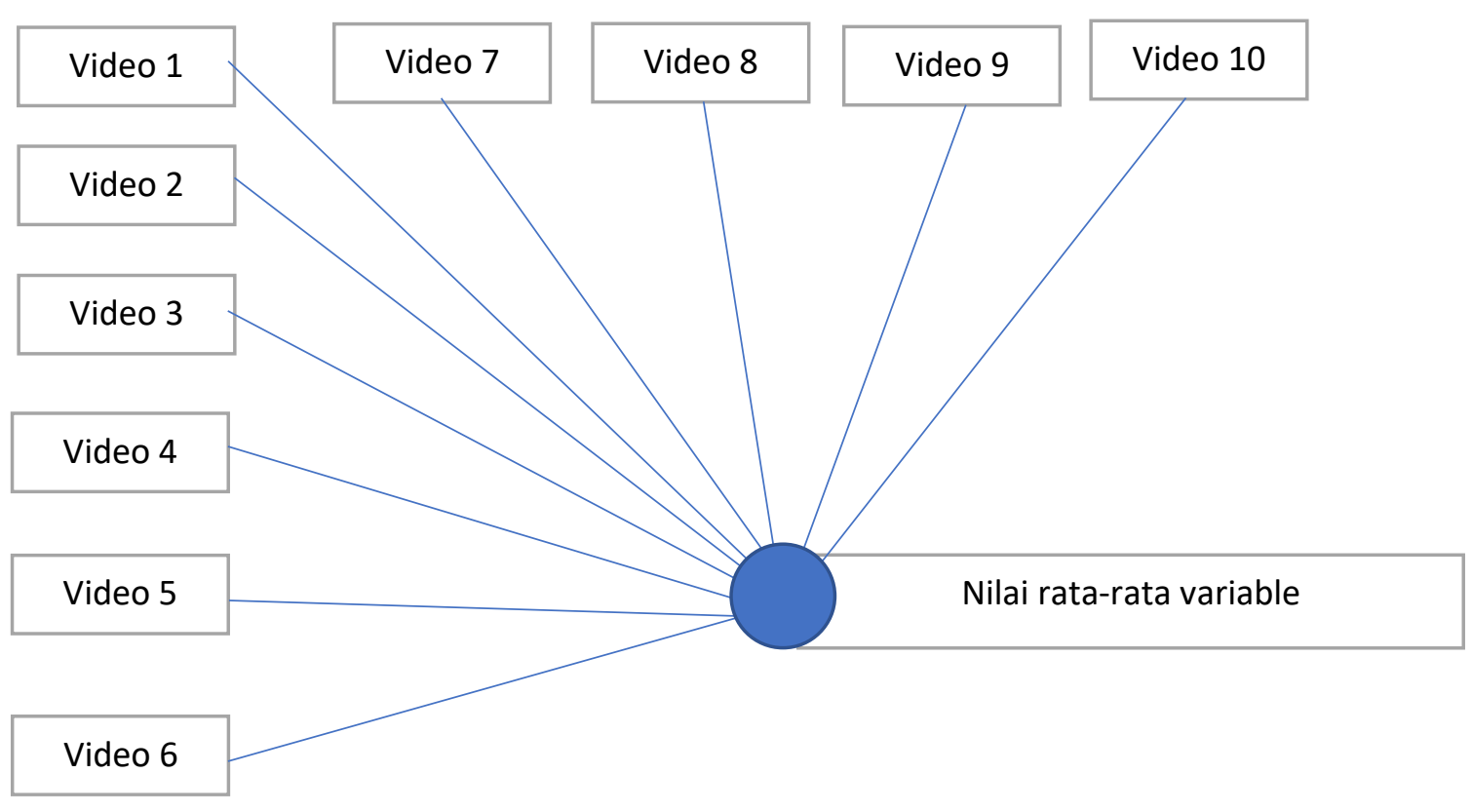




\section{c. Menghitung nilai kredibilitas rasio}

Dalam menghitung nilai dari video views to follower ratio, peneliti menggunakan cara membagi nilai rata-rata dari variable pertama dengan variable kedua, yakni membagi antara rata-rata video views dengan follower ratio

\section{d. Menentukan Peringkat Pada Akun Instagram.}

Pada langkah ini, dilakukan pemberian peringkat pada setiap rasio yang ada. Pada penentuan peringkat, yang perlu diperhatikan adalah karakteristik dari rasio yang di teliti. Objek yang memiliki nilai tertinggi akan mendapatkan angka 5 dan objek yang memiliki nilai ter rendah akan mendapatkan nilai 1, dan dalam pemberian ranking, objek yang memiliki nilai tertinggi akan mendapatkan ranking pertama sedangkan objek yang memiliki nilai rendah akan mendapatkan ranking terakhir.

\section{HASIL DAN PEMBAHASAN}

Akun Instagram dari 5 Brand Gaming Gear Lokal Terbaik, diantaranya:

\section{NYK NEMESIS}

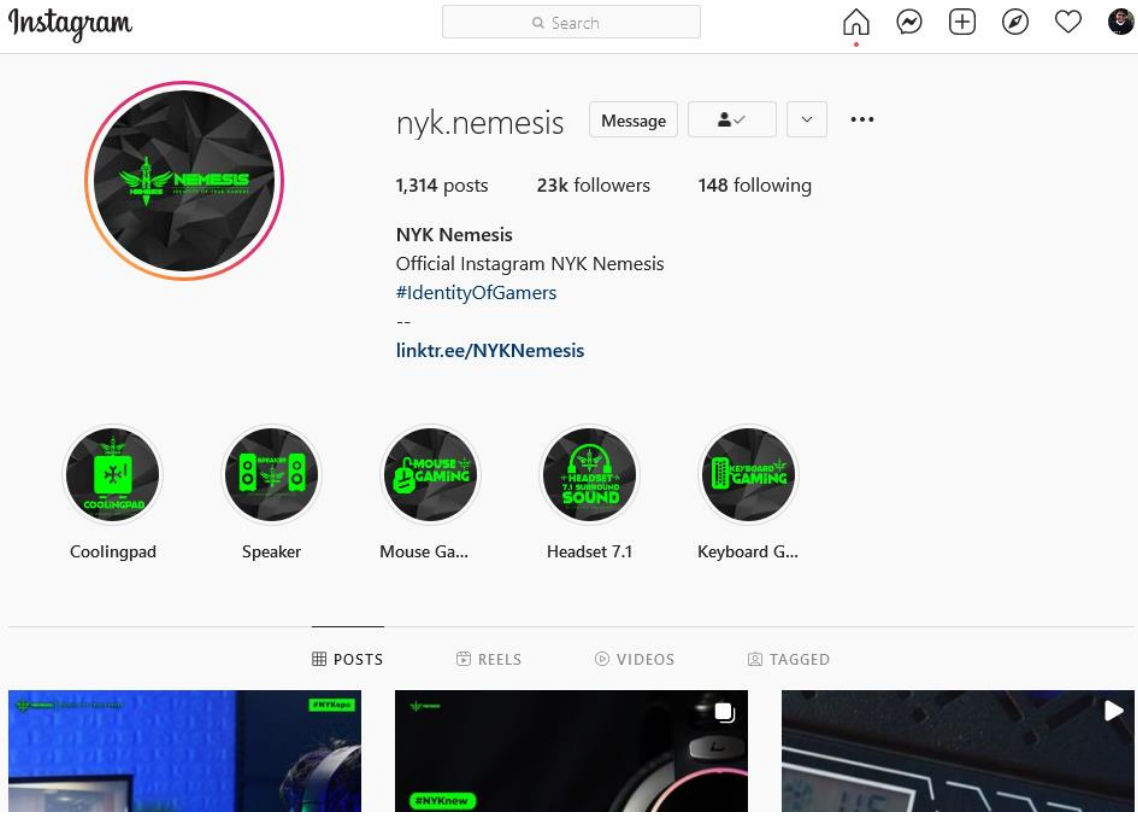

Gambar 1. Akun Instagram NYK NEMESIS

Sumber : https://www.instagram.com/nyk.nemesis/ (akses pada 10-20-2021) 


\section{REXUS ID}

Instagram

$$
\text { a search }
$$

$\Omega \oplus \oplus \oplus \circ$

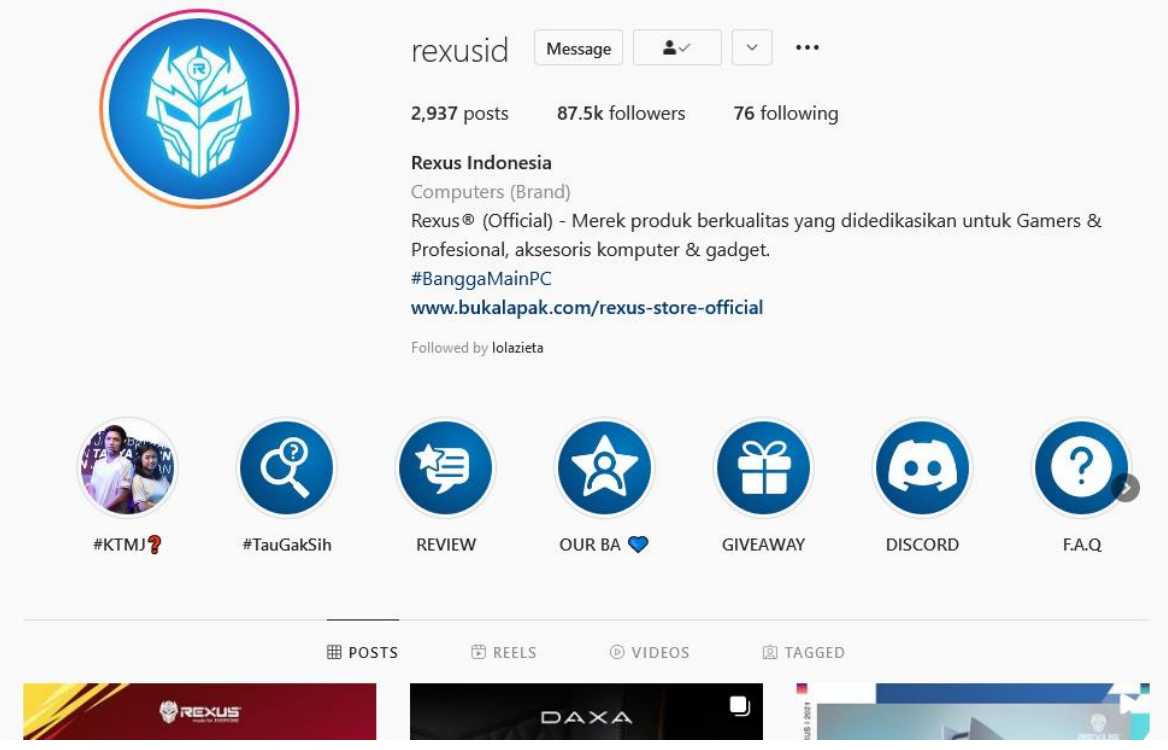

Gambar 2. Akun Instagram Rexus ID

Sumber : https://www.instagram.com/rexusid/ (akses pada 10-20-2021)

\section{Fantech ID}

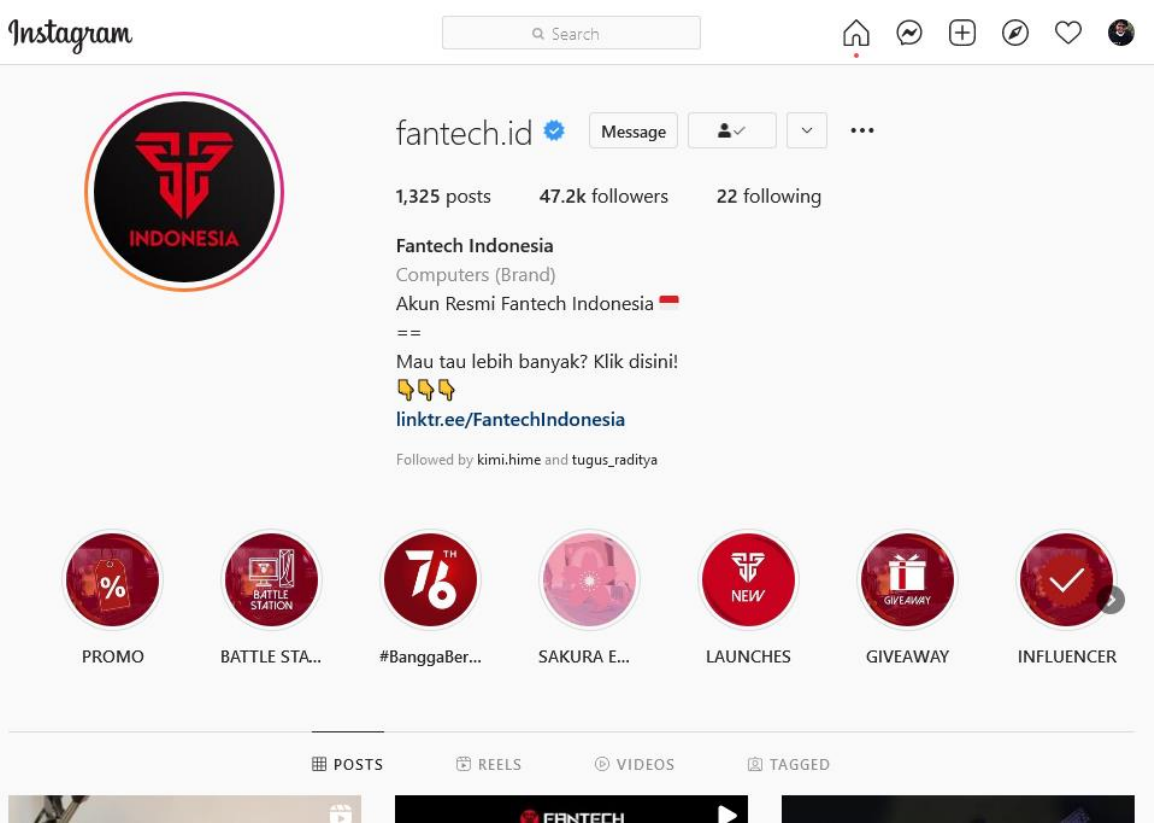

Gambar 3. Akun Instagram Fantech ID

Sumber : https://www.instagram.com/fantech.id/ (akses pada 10-20-2021) 


\section{DIGITAL ALIANCE}

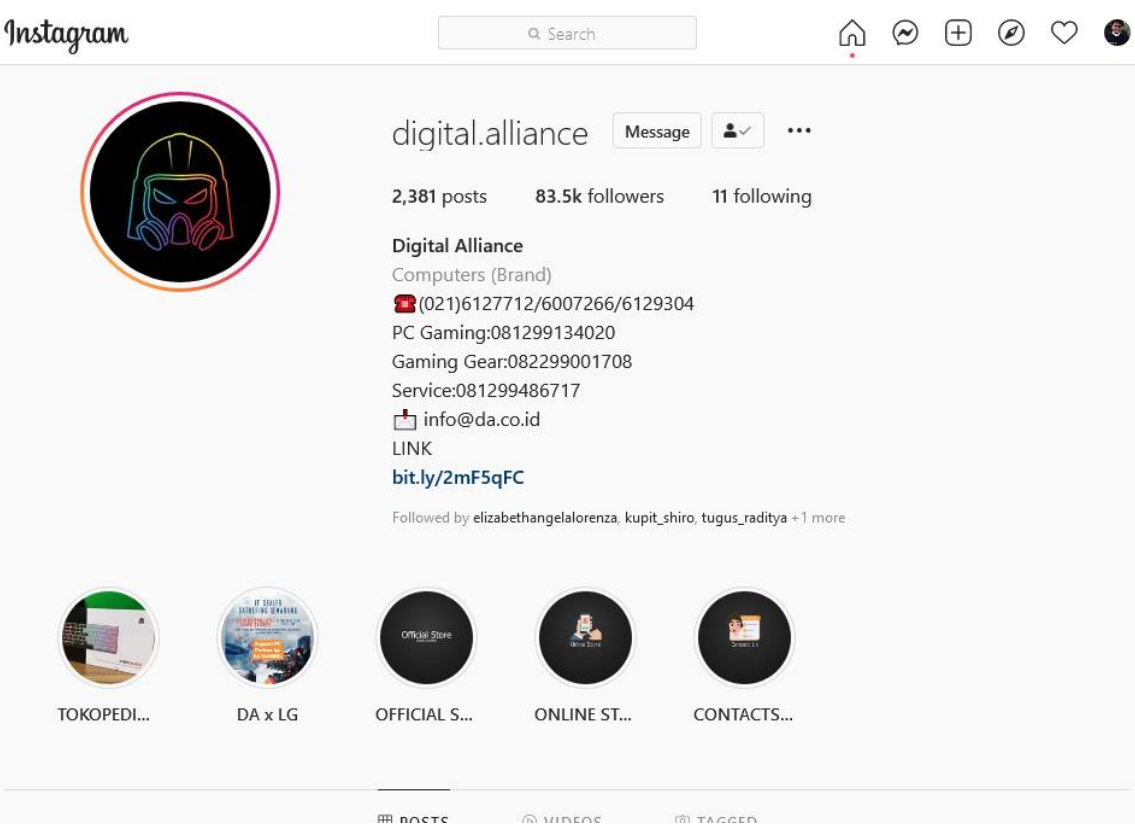

Gambar 4. Akun Instagram DIGITAL ALIANCE

Sumber : https://www.instagram.com/digital.alliance/ (akses pada 10-20-2021)

\section{VORTEX ID}

Instagram
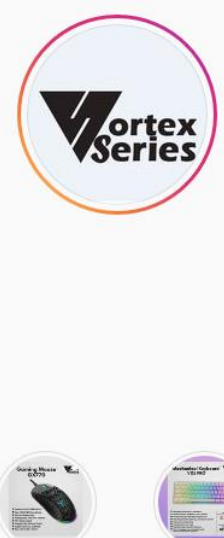

Gaming Mo...

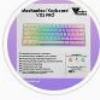

Mecha Key... a Search
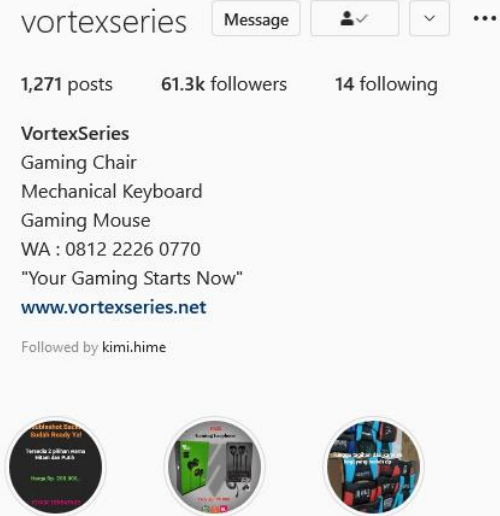

News

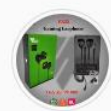

Gaming Ear..

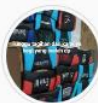

Bordir

\section{囲 POSTS}

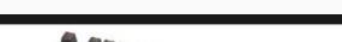

(2) VIDEOS

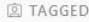

Gambar 4. Akun Instagram VORTEX ID

Sumber : https://www.instagram.com/vortexseries/ (akses pada 10-20-2021) 
Dari kelima akun Instagram 5 Brand Gaming Gear Lokal Terbaik, peneliti menemukan nilai dari masing-masing variabel yang ada untuk menghitung rasio Video Views to Followers Ratio dari setiap akun. Pada akun akun Instagram 5 Brand Gaming Gear Lokal Terbaik, diantaranya yaitu :

1. Likes

2. Followers

3. Following

4. Video Likes

5. Video Comments

6. Video Share

7. Video Views

8. Image Likes

9. Image Comments

10. Image Share

Dari ketujuh variabel tersebut peneliti hanya fokus untuk menemukan hasil dari 2 variabel, yaitu :

1. Video Views

2. Followers

Dari kedua variable tersebut kemudian akan dianalisa sehingga menemukan nilai rata-rata dari variable video views dan jumlah variable dari Followers. Untuk menghitung nilai ratarata dari video views, penulis mengambil 10 atau kurang sample yang berupa postingan video, yang kemudian diolah dengan cara dihitung sehingga memenukan nilai rata-rata dari video views. Berikut merupakan tabel nilai rata-rata dari masing-masing brand Gaming Gear Lokal Terbaik, yaitu:

Tabel 1. Analisa Nilai Rata-Rata Nilai Variabel Video Views Akun Instagram NYK NEMESIS 


\begin{tabular}{|c|c|}
\hline NO & Video Views \\
\hline 1 & 573 \\
\hline 2 & 484 \\
\hline 3 & 10.000 \\
\hline 4 & 288 \\
\hline 5 & 11.000 \\
\hline 6 & 36.500 \\
\hline 7 & 474 \\
\hline 8 & 4.388 \\
\hline 9 & 10.200 \\
\hline 10 & 712 \\
\hline Total & $\mathbf{7 . 4 6 2}$ \\
\hline
\end{tabular}

Sumber : Pengolah Data Excel

Tabel 2. Analisa Nilai Rata-Rata Nilai Variabel Video Views Akun Instagram REXUS ID

\begin{tabular}{|c|c|}
\hline NO & Video Views \\
\hline 1 & 573 \\
\hline 2 & 484 \\
\hline 3 & 10.000 \\
\hline 4 & 288 \\
\hline 5 & 11.000 \\
\hline 6 & 36.500 \\
\hline 7 & 474 \\
\hline 8 & 4.388 \\
\hline 9 & 10.200 \\
\hline 10 & 712 \\
\hline Total & $\mathbf{7 . 4 6 2}$ \\
\hline
\end{tabular}

Sumber : Pengolah Data Excel

Tabel 3. Analisa Nilai Rata-Rata Nilai Variabel Video Views Akun Instagram Fantech ID

\begin{tabular}{|c|c|}
\hline NO & $\begin{array}{c}\text { Video } \\
\text { Views }\end{array}$ \\
\hline 1 & 3.390 \\
\hline 2 & 2.793 \\
\hline 3 & 3.871 \\
\hline 4 & 9.650 \\
\hline 5 & 15.000 \\
\hline 6 & 4.625 \\
\hline 7 & 12.300 \\
\hline
\end{tabular}




\begin{tabular}{|c|c|}
\hline 8 & 12.600 \\
\hline 9 & 7.807 \\
\hline 10 & 16.300 \\
\hline Total & $\mathbf{8 . 8 3 4}$ \\
\hline
\end{tabular}

Sumber : Pengolah Data Excel

Tabel 4. Analisa Nilai Rata-Rata Nilai Variabel Video Views Akun Instagram Digital

Alliance

\begin{tabular}{|c|c|}
\hline NO & $\begin{array}{c}\text { Video } \\
\text { Views }\end{array}$ \\
\hline 1 & 1.075 \\
\hline 2 & 2.979 \\
\hline 3 & 817 \\
\hline 4 & 6.533 \\
\hline 5 & 982 \\
\hline 6 & 31.044 \\
\hline 7 & 1.558 \\
\hline 8 & 2.077 \\
\hline 9 & 5.884 \\
\hline 10 & 110 \\
\hline Total & $\mathbf{5 . 3 0 6}$ \\
\hline
\end{tabular}

Sumber : Pengolah Data Excel

Tabel 5. Analisa Nilai Rata-Rata Nilai Variabel Video Views Akun Instagram Vortex Series

\begin{tabular}{|c|c|}
\hline NO & Video Views \\
\hline 1 & 19.445 \\
\hline 2 & 6.987 \\
\hline Total & $\mathbf{1 3 . 2 1 6}$ \\
\hline
\end{tabular}

Sumber : Pengolah Data Excel

Setelah menghitung nilai rata-rata tersebut, maka akan menemukan hasil akhir nilai ratarata dari variabel video views dan jumlah variable Followers. 
Tabel 8. Nilai Variabel Pada Akun Instagram 5 Brand Gaming Gear Lokal Terbaik

\begin{tabular}{|c|c|c|c|c|c|}
\hline Variable & NYK NEMESIS & REXUS ID & Fantech ID & Digital Alliance & Vortex Series \\
\hline Video Views & 7.462 & 4.107 & 8.834 & 5.306 & 13.216 \\
\hline Follower & 23.200 & 87.500 & 47.100 & 83.600 & 61.100 \\
\hline
\end{tabular}

Sumber : Pengolah Data Excel

Untuk menghitung kredibilitas dari masing-masing akun Instagram setiap Brand Gaming Gear, peneliti menghitung dengan cara : variabel 1 akan dibagi dengan variabel 2, sehingga ditemukan hasil analisisa dari rasio tersebut.

Tabel 9. Hasil Perhitungan Rasio Akun Instagram

\begin{tabular}{|c|c|c|c|c|c|c|}
\hline Ratio & NYK NEMESIS & REXUS ID & Fantech ID & Digital Alliance & Vortex Series & Karakteristik \\
\hline Video Views to Followers Ratio & 0,321637931 & 0,046937143 & 0,187558386 & 0,0634689 & 0,216301146 & Tinggi \\
\hline
\end{tabular}

Sumber : Pengolah Data Excel

Video Views To Follower Ratio memiliki karakteristik yang Tinggi, artinya semakin tinggi nilai yang dihasilkan maka semakin baik kredibilitas dari performa akun tersebut. Untuk memberikan peringkat pada masing-masing Brand Gaming Gear, peneliti memberikan angka 5 kepada brand yang mendapatkan nilai tertinggi dan angka 1 untuk brand smartphone yang mendapatkan nilai terendah. Berikut merupakan tabel urutan nilai yang dihasilkan oleh masing-masing brand Gaming Gear.

Tabel 10. Nilai Rasio Instagram Pada 5 Brand Gaming Gear Lokal Terbaik

\begin{tabular}{|l|c|}
\hline \multicolumn{2}{|c|}{ Table Peringkat } \\
\hline NYK NEMESIS & 5 \\
\hline REXUS ID & 1 \\
\hline Fantech ID & 3 \\
\hline Digital Alliance & 2 \\
\hline Vortex Series & 4 \\
\hline
\end{tabular}

Sumber : Pengolah Data Excel

Dari Tabel Nilai Rasio Instagram Pada 5 Brand Gaming Gear Lokal Terbaik dapat simpulkan bahwa NYX NEMESIS mendapatkan nilai tertinggi untuk rasio Video Views to Followers. Sedangkan akun Instagram REXUS ID mendapatkan nilai terendah untuk rasio ini. Jadi, pada penelitian ini NYX NEMESIS memiliki kredibilitas performa yang lebih baik dibandingkan dengan brand Gaming Gear yang lainnya. 


\section{KESIMPULAN}

Tujuan dari penelitian ini adalah mengetahui kredibilitas performa dari akun Instagram Pada 5 Brand Gaming Gear Lokal Terbaik menggunakan Video Views to Followers Ratio. 5 Brand Gaming Gear Lokal Terbaik:NYX NEMEIS, Vortex Series, Fantech ID, Digital Aliance, dan REXUS ID. Dari ketujuh brand smartphone tersebut dapat disimpulkan bahwa :

1. Peringkat pertama diraih oleh NYK NEMESIS dengan nilai 0,321637931

2. Peringkat kedua diraih oleh Vortex Series dengan nilai 0,216301146

3. Peringkat ketiga diraih oleh Fantech ID dengan nilai 0,187558386

4. Peringkat keempat diraih oleh Digital Alliance dengan nilai 0,0634689

5. Peringkat kelima diraih oleh REXUS ID dengan nilai 0,046937143 


\section{Daftar Pustaka}

Ernayani, Rihfenti, Achmad Daengs GS, Nuah P. Tarigan, Winda Lestari, and Elkana Timotius. 2021. "Kajian Fenomenologi Pemasaran Digital Agen Properti Melalui Medium Instagram." Jurnal Komunikasi Profesional 5 (3): 260-69. https://doi.org/10.25139/jkp.v5i3.3804.

“Inilah 5 Brand Gaming Gear Lokal Terbaik - EXP.” n.d. Accessed October 28, 2021. https://exp.itemku.com/5-gaming-gear-lokal-terbaik/.

Kertamukti, Rama, Dosen Ilmu, Komunikasi Uin, and Sunan Kalijaga. 2015. "INSTAGRAM DAN PEMBENTUKAN CITRA (Studi Kualitatif Komunikasi Visual Dalam Pembentukan Personal Karakter Account Instagram @basukibtp)” 08 (01): 57-66.

Ruth, Debra, and Diah Ayu Candraningrum. 2020. "Pengaruh Motif Penggunaan Media Baru Tiktok Terhadap Personal Branding Generasi Milenial Di Instagram.” Koneksi 4 (2): 207. https://doi.org/10.24912/kn.v4i2.8093.

Sari, Anggi Damora. 2021. "Pemanfaatan Media Pembelajaran Dengan Menggunakan Fitur ‘ Reels Instagram ’ Pada Pembelajaran Bahasa Dan Sastra Indonesia Di Masa Pandemi Covid-19." http://digilib.unimed.ac.id/43369/1/Fulltext.pdf.

Soraya, Iin. 2017. "Personal Branding Laudya Cynthia Bella Melalui Instagram (Studi Deskriptif Kualitatif Pada Akun Instagram @ Bandungmakuta).”Jurnal Komunikasi 8 (2): 30-38. http://ejournal.bsi.ac.id/ejurnal/index.php/jkom/article/view/2654.

Untari, Dewi, and Dewi Endah Fajariana. 2018. "Strategi Pemasaran Melalui Media Sosial Instagram (Studi Deskriptif Pada Akun @Subur_Batik)."Widya Cipta: Jurnal Sekretari Dan Manajemen 2 (2): 271-78. https://ejournal.bsi.ac.id/ejurnal/index.php/widyacipta/article/view/4387.

Yusi Kamhar, Muhammad, and Erma Lestari. 2019. "Pemanfaat Sosial Media Youtube Sebagai Media Pembelajaran Bahasa Indonesia DI Perguruan Tinggi." Inteligensi : Jurnal Ilmu Pendidikan 1 (2): 1-7. https://doi.org/10.33366/ilg.v1i2.1356. 